\title{
A pesca de acari (PTerygoplichthys pardalis) na várzea do Baixo Amazonas, Pará, Brasil: Aspectos estruturais e socioeconômicos
}

\author{
Ericleya Mota Marinho Lima ${ }^{1 *}$; Paulo Roberto Brasil Santos ${ }^{2}$, Tony Marcos Porto Braga ${ }^{3}$, \\ David GibBs McGrath ${ }^{4}$
}

\author{
1 Universidade Federal do Oeste do Pará, Programa de Pós-graduação Sociedade, Natureza e Desenvolvimento, Santarém, Pará, Brasil \\ 2 Universidade Federal do Oeste do Pará, Instituto de Ciências e Tecnologia das Águas, Campus Monte Alegre, Pará, Brasil \\ 3 Universidade Federal do Oeste do Pará, Instituto de Ciências e Tecnologia das Águas, Santarém, Pará \\ 4 Universidade Federal do Oeste do Pará, Instituto de Ciências da Sociedade, Santarém, Pará, Brasil \\ * Autorpara correspondência: ericleyamotamarinho@hotmail.com
}

Recebido em 01 de novembro de 2019. Aceito em 18 de dezembro de 2019. Publicado em 30 de dezembro de 2019.

Resumo - No Baixo Amazonas, a espécie Pterygoplichtbys pardalis, popularmente conhecida na região como acari, é uma das dez principais espécies das pescarias regionais e, por este motivo, o presente trabalho visou caracterizar a pesca desta espécie em três comunidades de várzea. Foram realizadas entrevistas semiestruturadas com pescadores para a obtenção de dados, bem como a medição do comprimento total $(\mathrm{cm})$ de espécimes. Constatou-se que a pesca de acari é importante tanto para o consumo quanto para a economia das famílias. As capturas ocorrem com mais frequência entre julho e novembro (período de vazante e seca) utilizando tarrafas. Os acaris, diferente da maioria dos peixes amazônicos, são comercializados vivos e em unidades. Em uma das comunidades também é vendido em forma de farinha (piracuî) produzida artesanalmente. Os lagos de várzea são os principais ambientes de captura da espécie ao longo do ano. Há diferenças significativas $(\mathrm{F}=13$; $\mathrm{p}=$ $\left.2,67 \times 10^{-6}\right)$ no comprimento médio corporal do acari entre as comunidades. Os resultados apresentados contribuem para o entendimento de como a pesca do acari se desenvolve atualmente na área de estudo e podem auxiliar no manejo e na conservação deste recurso de elevada importância pesqueira para o Baixo Amazonas.

Palavras-chave: Amazônia; pesca artesanal; planície inundável; gestão pesqueira.

Acari (Pterygoplichthys pardalis) fishing in the Lower Amazon floodplain, Pará, Brazil: Structural and SOCIOECONOMIC ASPECTS

Aвstract - In the Lower Amazon, the species Pterygoplichthys pardalis, popularly known in the region as acari, is one of the ten main species of regional fisheries and, for this reason, the present work aimed to characterize the fishing of this species in three floodplain communities. Semi-structured interviews were conducted with fishermen to obtain data as well as to measure the total length $(\mathrm{cm})$ of specimens. The acari fishing has been found to be important for both household consumption and the economy. Catches occur most frequently between July and November (ebb and dry season) using castnet. Acaris, unlike most Amazonian fish, are traded live and in units. In one of the communities is also sold as fish flour (named piracui) manually produced. It was found that there is a significant difference $(\mathrm{p}<0.01)$ in the average length of acaris among the communities $(\mathrm{F}=13 ; \mathrm{p}=2.67 \times 10-6)$. The results achieved contribute to the understanding of how acari fishing is currently being developed in the study area and may help in the management and conservation of this highly important resource for the Lower Amazon.

KEYwords: Amazon; artisanal fishing; floodplain; fisheries management. 
La pesca del pleco (Pterygoplichthys pardalis) en la llanura de inundación del bajo Amazonas, Pará, Brasil:

\section{AsPeCtOS ESTRUCTURALES Y SOCIOECONÓMICOS}

Resumen - En el Bajo Amazonas, la especie Pterygoplichtbyspardalis, conocida popularmente en la región como acari (pleco), es una de las diez especies principales de la pesca regional y, por esta razón, este trabajo tuvo como objetivo caracterizar la pesca de esta especie en tres comunidades de llanuras de inundación. Se realizaron encuestas semiestructuradas con pescadores para obtener datos y para medir la longitud total $(\mathrm{cm})$ de los especímenes. Se ha comprobado que la pesca del pleco es importante tanto para el consumo como para la economía familiar. Las capturas ocurren con mayor frecuencia entre julio y noviembre (reflujo y estación seca) utilizando tarrafas. Los plecos, a diferencia de la mayoría de los peces amazónicos, se comercializan vivos y en unidades. En una de las comunidades también se vende en forma de harina (llamada piracuí) producida a mano. Existen diferencias significativas $(F=13 ; p=2,67 \times 10-6)$ en la longitud media del cuerpo de los plecos entre las comunidades. Los resultados alcanzados contribuyen a la comprensión de cómo se está desarrollando actualmente la pesca de pleco en el área de estudio y pueden ayudar en la gestión y conservación de este recurso tan importante para el Bajo Amazonas.

Palabras clave: Amazonia; pesca artesanal; llanura de inundación; manejo pesquero.

\section{INTRODUÇÃO}

No Baixo Amazonas, a espécie Pterygoplichthys pardalis (Castelnau, 1855) conhecida popularmente como acari é uma das principais espécies registradas nos desembarques dos portos da região, com captura anual de aproximadamente 300 toneladas (Ruffino et al. 2006; Tomé-Souza et al. 2007). Importante comercialmente, o acari tem o período da sua reprodução protegido pela Instrução Normativa N $^{\circ} 22$ de 04 de julho de 2005, a qual proíbe anualmente no período de $1^{\circ}$ de dezembro a 30 de março, a pesca, o transporte, a comercialização e o armazenamento desta espécie nos municípios ao longo do Rio Amazonas, no Estado do Pará.

Na várzea da região, o acari é a espécie mais frequente nas capturas das comunidades ribeirinhas com estimativa de produção anual de até uma tonelada em algumas comunidades (Castello et al. 2013). As consequências dessa pressão tem sido revelada em estudos biológicos da espécie que mostram a diminuição acentuada do comprimento médio corporal dos acaris nas comunidades onde são mais capturados, indicando com isso sinais típicos de sobreexplotação dos estoques (Castello et al. 2011).

O acari apresenta característica peculiar de venda, sendo comercializado vivo, em função do rápido processo de degradação após a sua morte, o que origina um forte odor que inviabiliza seu consumo (Lourenço et al. 2011). De acordo com Braga et al. (2016), nos mercados de peixes da cidade de Santarém, principal porto de desembarque pesqueiro do Baixo Amazonas, os vendedores bem como os consumidores confirmam que antigamente a preferência da população era pelo acari, porém destacam que nos dias atuais essa preferência tem mudado em virtude da indisponibilidade do produto no mercado. Além disso, a maior frequência de exemplares pequenos nas feiras, quando o produto está disponível, também tem contribuído para a mudança no consumo da espécie, visto que o consumidor tem preferência por acaris maiores.

Diante da importância que o acari tem para a região, faz-se necessário a busca por conhecimentos que contribuam para a compreensão da pesca do acari, possibilitando que uma base de informações sobre a espécie seja criada e que medidas de manejo possam ser adotadas ou aprimoradas visando a pesca sustentável deste recurso pesqueiro. Com vistas a contribuir com estes conhecimentos, este estudo teve como objetivo caracterizar a pesca de acari (Pterygoplichthys pardalis) em três comunidades de várzea do Baixo Amazonas. Tal caracterização destaca os aspectos sobre o perfil dos pescadores, as fontes de renda, estimativa de captura, os ambientes de pesca, os tipos de embarcações utilizados nas pescarias, bem como o tipo de apetrecho empregado e o processo de comercialização do pescado. 


\section{Material e mÉtodos}

Area de estudo

O presente estudo foi realizado em três comunidades da várzea do Baixo Amazonas, município de Santarém e Alenquer, Estado do Pará. O Baixo Amazonas compreende a região que se estende ao longo do rio Amazonas, desde a foz do rio Madeira até a foz do rio Xingu (Verner 2004). A várzea compõe os ecossistemas aquáticos amazônicos cuja principal característica é representada pelo pulso de inundação e abrange a área que alaga anualmente pelo transbordamento dos rios de água branca da calha principal para suas margens laterais (Junk et al. 1989).

A paisagem da várzea sofre variação cíclica devido à flutuação anual do nível do rio, resultante da chuva em toda a bacia (Junk et al. 1989). O regime fluvial consiste em quatro estações (enchente, cheia, vazante e seca) que apesar da sua previsibilidade, o período e a duração de cada uma varia a cada ano. Assim, os moradores dessas áreas, conhecidos como varzeiros ou ribeirinhos, têm um modo de vida adaptado às condições do ambiente e combinam diferentes atividades produtivas ao longo do ano de acordo com a dinâmica do rio (Castro e McGrath 2001).

A paisagem da várzea é composta por quatro principais zonas ecológicas que são utilizadas de modo diferente entre os moradores, são elas: os canais, as restingas, os campos naturais e os lagos (Figura 1). Os canais são rios e riachos de livre acesso, usados para o transporte e para a pesca comercial. As restingas por sua vez, são os terrenos mais elevados que margeiam os canais onde se localizam as casas e onde se desenvolve a atividade agrícola. Os campos naturais ocupam a zona entre as restingas e os lagos, sendo usados como área de pastagem natural. Os lagos são utilizados tanto para a pesca comercial quanto para a de subsistência (McGrath et al. 1993).

Figura 1. Ambientes e uso da terra na várzea do Baixo Amazonas.

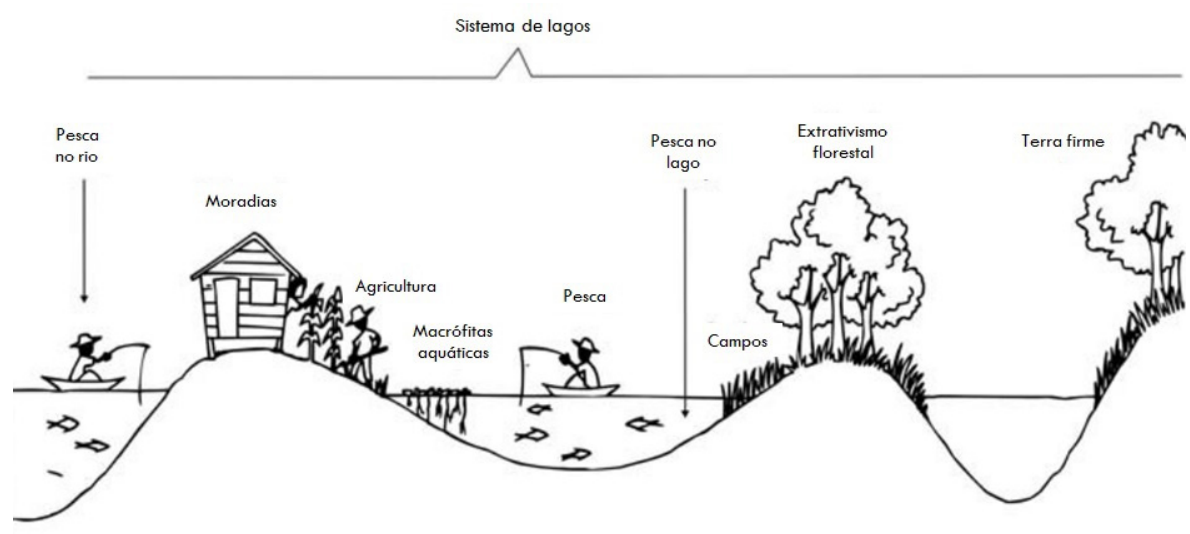

Fonte: McGrath et al. (2008).

Os lagos são ambientes bastante importantes para a pesca na várzea. Nos municípios do Baixo Amazonas, as comunidades que partilham o mesmo sistema de lagos formaram Conselhos Regionais de Pesca compostos por representantes de cada comunidade e das Colônias de Pescadores. Em 2005 e 2006, o território de cada sistema de lagos foi transformado em Projetos de Assentamento Agroextrativistas (PAE), definidos como territórios de uso coletivo prioritário aos moradores do PAE. Cada PAE é subdividido em territórios comunitários informais (McGrath et al. 2008).

O Projeto de Assentamento Agroextrativista é uma modalidade de assentamento estabelecida pelo Instituto Nacional de Colonização e Reforma Agrária (INCRA) pela portaria Nº268 de 23 de outubro de 1996, concebido para regularizar a situação fundiária de populações tradicionais que ocupam territórios pertencentes à União. 
Neste estudo, as comunidades estudadas foram Pixuna do Tapará e Tapará Miri, integrantes do PAE-Tapará no município de Santarém, e a Comunidade Salvação, integrante do PAE-Salvação no município de Alenquer (Figura 2).

Figura 2. Localização das comunidades estudadas em dois municípios do Pará, Norte do Brasil.
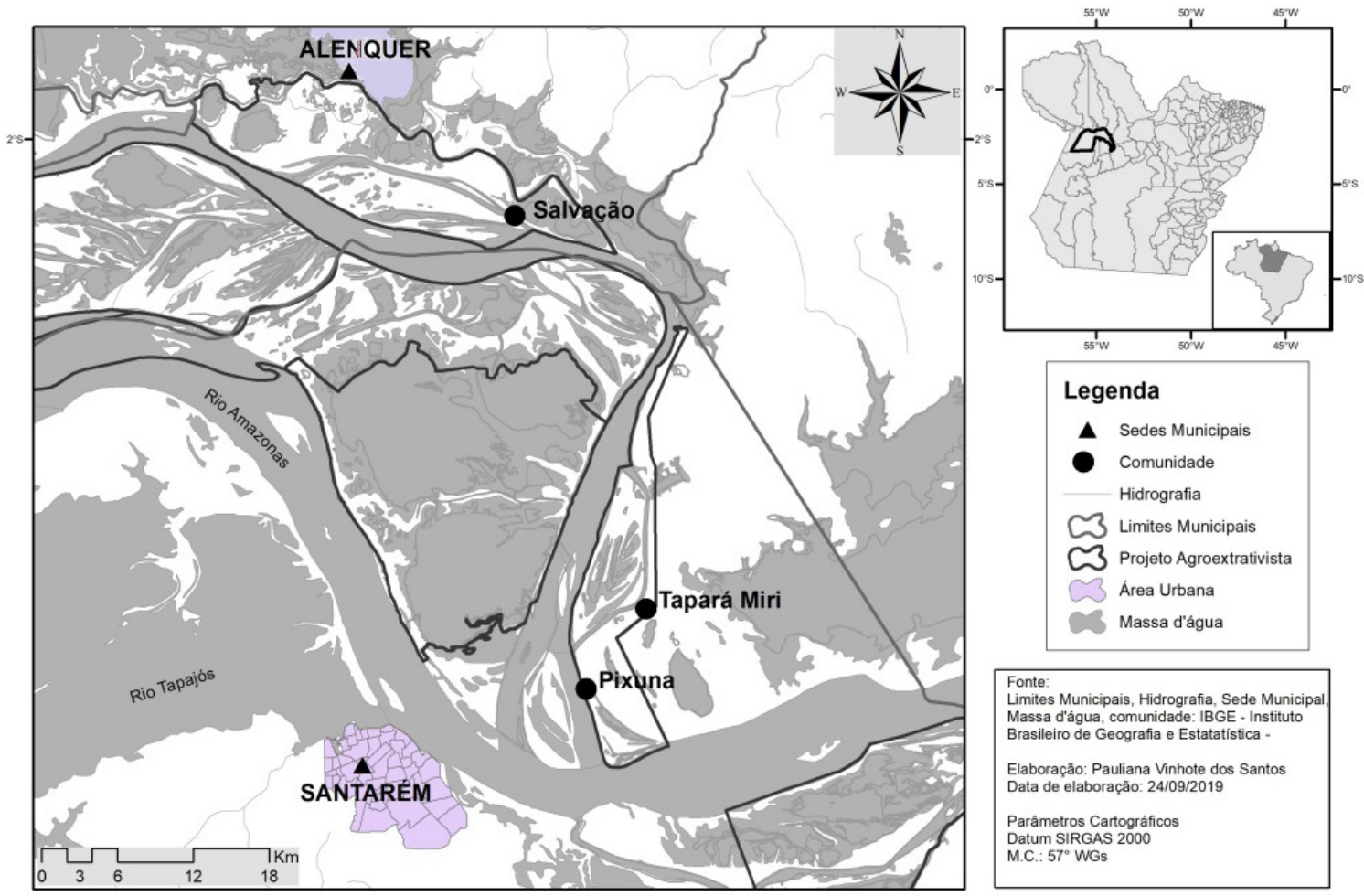

\section{Coleta e análise de dados}

Os dados para a realização deste estudo foram coletados em diferentes momentos, os quais são descritos a seguir:

O primeiro momento consistiu no monitoramento participativo da pesca para o registro das capturas de acari (kg) e dos ambientes de pesca nas três comunidades durante uma semana de cada mês amostrado, totalizando seis meses amostrados na Comunidade Salvação e sete meses nas demais, no período entre maio de 2017 a fevereiro de 2018. O monitoramento participativo da pesca é apontado com um método confiável e de menor custo para avaliação da pesca artesanal nas comunidades ribeirinhas, segundo Carvalho et al. (2009). Difere do monitoramento pesqueiro convencional, pois é realizado pelos próprios comunitários e não por pesquisadores ou agentes do governo, sendo estes apenas colaboradores, e prescinde de uma relação de confiança entre pescadores e coletores dos dados (Raseira 2007; McCluskey e Lewinson 2008).

Foram registradas pescarias da última semana de cada mês com cerca de $20 \%$ das famílias de pescadores de cada comunidade, conforme a metodologia de Martelo et al. (2008) e Castello et al. (2011, 2013). As Comunidades Salvação, Tapará Miri e Pixuna do Tapará são constituídas por 103, 70 e 78 famílias, respectivamente. Nas comunidades que apresentam até 80 famílias foram selecionadas 14 famílias para registro das pescarias; e na comunidade com mais de 80 famílias selecionou-se 16 famílias de pescadores, sendo os registros feitos com um dos chefes da casa. A seleção das famílias ocorreu após indicação voluntária das mesmas durante reuniões comunitárias.

O segundo momento consistiu em entrevistas semiestruturadas realizadas por uma pesquisadora com os pescadores das comunidades alvo do estudo. Este método combina perguntas fechadas e abertas, em que o entrevistado tem a possibilidade de discorrer sobre o tema em questão sem se prender à indagação formulada 
(Minayo 2009). As entrevistas seguiram um roteiro previamente elaborado composto por perguntas que abordaram aspectos socioconômicos dos pescadores e aspectos da pesca do acari. Foram entrevistados 24 pescadores na Comunidade Salvação, 15 no Tapará Miri e 17 no Pixuna, entre abril a maio de 2019.

Estas entrevistas foram realizadas individualmente com pescadores experientes selecionados inicialmente a partir da indicação da liderança da comunidade. Em conjunto com os primeiros entrevistados, foi elaborada uma lista com nomes de outros pescadores para serem entrevistados, estes também indicaram outros pescadores e assim sucessivamente. Este método denominado "bola de neve" consiste em solicitar, ao final de cada entrevista, que o informante indique um ou mais pescadores de sua comunidade que sejam os mais experientes e que tenham a pesca como uma das suas principais atividades (Bailey 1982).

No terceiro momento foi feita amostragem populacional de espécimes de acari nas comunidades, entre o período de setembro de 2018 a abril de 2019. Os peixes foram coletados das pescarias realizadas pelos próprios pescadores. Para cada peixe foi registrado o comprimento total $(\mathrm{cm})$, a partir da medição que se deu desde a extremidade do focinho do peixe até o extremo posterior da nadadeira caudal, com auxílio de um ictiômetro. Foram ainda utilizados os dados da cota mensal do nível do rio Amazonas dos anos de 2017 e 2018, obtidos junto ao site da Agência Nacional da Águas (ANA) a fim de relacionar as capturas de acari e os ambientes de pesca com o regime fluvial.

Todos os dados obtidos foram armazenados em planilhas eletrônicas e analisados através da estatística descritiva, com cálculo de frequência relativa, medida de tendência central (média) e de dispersão dos dados (Morettin e Bussab 2010). Para os dados da amostragem populacional foi utilizada ANOVA One-way com uso do Software PAST versão 2.17 para verificar diferenças significativas $(\alpha<0,01)$ no comprimento dos espécimes entre as comunidades. O teste Tukey foi utilizado para análises a posteriori. O projeto deste estudo foi submetido ao Comitê de Ética em Pesquisa (CEP) através da plataforma Brasil, do Ministério da Saúde e recebeu parecer favorável e licença $\mathrm{N}^{\circ}$ 3.271.911.

\section{Resultados e Discussão}

\section{Perfil dos pescadores e fontes de renda}

O perfil dos pescadores foi obtido a partir de um total de 56 entrevistas nas três comunidades estudadas, incluindo 07 mulheres (12,5\%) e 49 homens (87,5\%). A baixa participação das mulheres na atividade evidenciada pode estar relacionada com algumas dificuldades apontadas por Rocha e Poleto (2009) neste ramo, como por exemplo, a necessidade de maior resistência física e força para manuseio dos apetrechos de pesca. Além disso, fatores culturais podem também contribuir para esta realidade, pois em comunidades rurais geralmente o papel desempenhado pelas mulheres é voltado para trabalhos considerados mais "leves" e para a administração e execução de tarefas domésticas (O’Dwyer 2005; Castro et al. 2007).

A idade dos entrevistados teve média de 46,37 ( \pm 12,96) anos. Estes iniciaram suas atividades na pesca com idade média de 13,82 ( \pm 6,22) anos e desenvolvem a atividade em média 32,57 $( \pm 11,89)$ anos. Isto evidencia que os pescadores indicados como sendo especialistas, de fato possuem conhecimento sobre a pesca devido à elevada média de idade e de experiência na atividade. Geralmente, a pesca representa a principal atividade econômica e de subsistência para esses pescadores, por isso apresentam longo tempo de dedicação a este exercício, característica que pode ser constatada em outros estudos (Cardoso e Freitas 2012; Lima et al. 2012; Hallwass et al. 2019).

Quanto à escolaridade, a maioria (81\%) não concluiu o ensino fundamental. Os níveis encontrados não diferem de outras localidades da Amazônia (Inomata e Freitas 2015; Vaz et al. 2017; Serrão et al. 2019) e outras regiões do Brasil (Alencar e Maia 2011; Ramires et al. 2012; Acauan et al. 2018). O baixo nível de escolaridade contribui para 
a permanência dos pescadores na atividade pesqueira e compromete sua mudança para outras profissões mais bem remuneradas devido à falta de qualificação (Lima et al. 2012).

Além da pesca, os pescadores das três comunidades têm outras fontes de renda (Figura 3), com destaque para a agricultura, benefícios do governo (aposentadoria e bolsa família) e diárias (ex: capina, roçado e colheita). Nenhum informante declarou que depende exclusivamente da pesca. Estes resultados corroboram com a caracterização de Almeida et al. (2006) que também identificaram a agricultura, a criação de animais de pequeno porte e os benefícios do governo, como outras fontes de renda mais citadas por pescadores na mesma região.

Figura 3. Fontes de renda dos pescadores além da pesca.

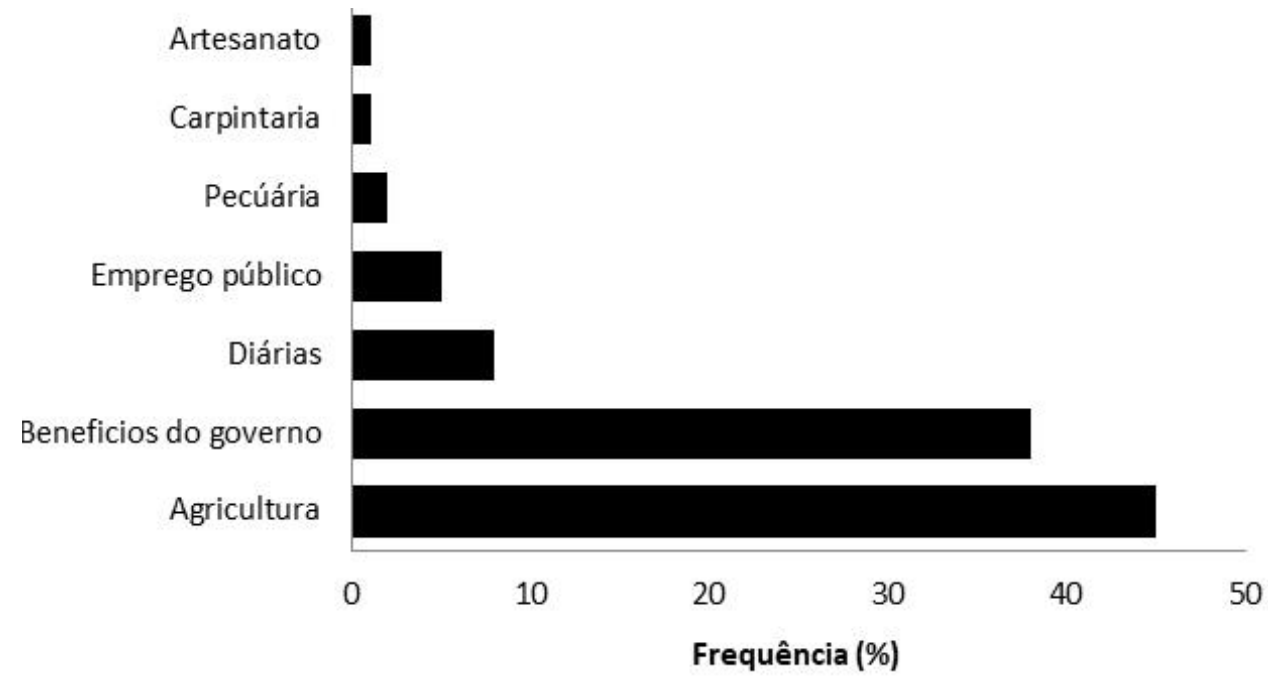

$\mathrm{Na}$ várzea, a diversificação de atividades praticadas para garantir o sustento das famílias, tem como objetivo reduzir os riscos e de se adaptar à sazonalidade da disponibilidade de recursos e de suas zonas ecológicas (McGrath et al. 2008). Furtado (1993) afirma que os pescadores artesanais de comunidades ribeirinhas são denominados polivalentes devido à multiplicidade de tarefas realizadas ao longo do ano, onde associam atividades que permitem a comercialização de vários produtos para garantir uma renda mínima.

A agricultura é realizada por $71 \%$ dos entrevistados, com ênfase para a plantação de milho (Zea mays), jerimum (Cucurbita sp.) e melancia (Citrullus lanatus), produtos que são utilizados pelos comunitários tanto para fins de subsistência quanto para a comercialização. Esse destaque da agricultura entre a dinâmica de atividades praticadas pelos pescadores rurais de pequena escala também é percebida em outras localidades da Amazônia (Pereira et al. 2007; Zacardi et al. 2014; Silva e Braga 2016).

$\mathrm{Na}$ várzea, as plantações são realizadas anualmente, em um tempo relativamente curto (seis meses), à medida que o nível do rio diminui e o os ambientes ficam disponíveis para o os plantios antes da próxima inundação. Esse fator ambiental influencia a escolha dos produtos cultivados, por isso os habitantes optam pelas culturas de crescimento rápido tais como o milho, o feijão, o jerimum, a melancia, entre outras (Castro e McGrath, 2001).

\section{Captura de acari}

Todos os entrevistados foram unânimes em afirmar que a pesca do acari varia ao longo do ano, sendo mais frequente no período em que o nível das águas dos rios começa a baixar (vazante), meados de junho, até atingir o seu menor nível (seca), no mês de novembro. Isto também foi observado em 397 registros de pescarias feitos no primeiro momento do trabalho (Figura 4). A maior frequência de pescarias nesse período se dá pela relativa facilidade de captura, uma vez que os ambientes aquáticos da várzea se reduzem e os peixes tendem a se concentrar, tornando-os mais vulneráveis aos apetrechos de pesca (Isaac et al. 2004). 
Nos meses referentes ao período de enchente (dezembro a abril) as pescarias de acari são raras, voltadas mais para o consumo familiar, e isto está relacionado com o período de defeso da espécie que se estende de dezembro a março, onde a pesca para a comercialização é proibida, de acordo com Instrução Normativa $N^{\circ} 22$ de 04 de julho de 2005 do Ministério do Meio Ambiente. Os pescadores também afirmam que evitam capturar o acari para o consumo nessa época, pois o peixe encontra-se muito magro e sem sabor em razão da desova que ocorre nesse período. Sobre essa constatação, Vazzoler (1996) afirma que nos peixes, a energia disponível armazenada em forma de gordura que é acumulada durante a cheia quando os peixes estão se alimentando intensamente é consumida durante o período reprodutivo para a maturação das gônadas, por isso os peixes ficam magros após a desova.

Figura 4. Captura (kg) de acari ao longo do ano.

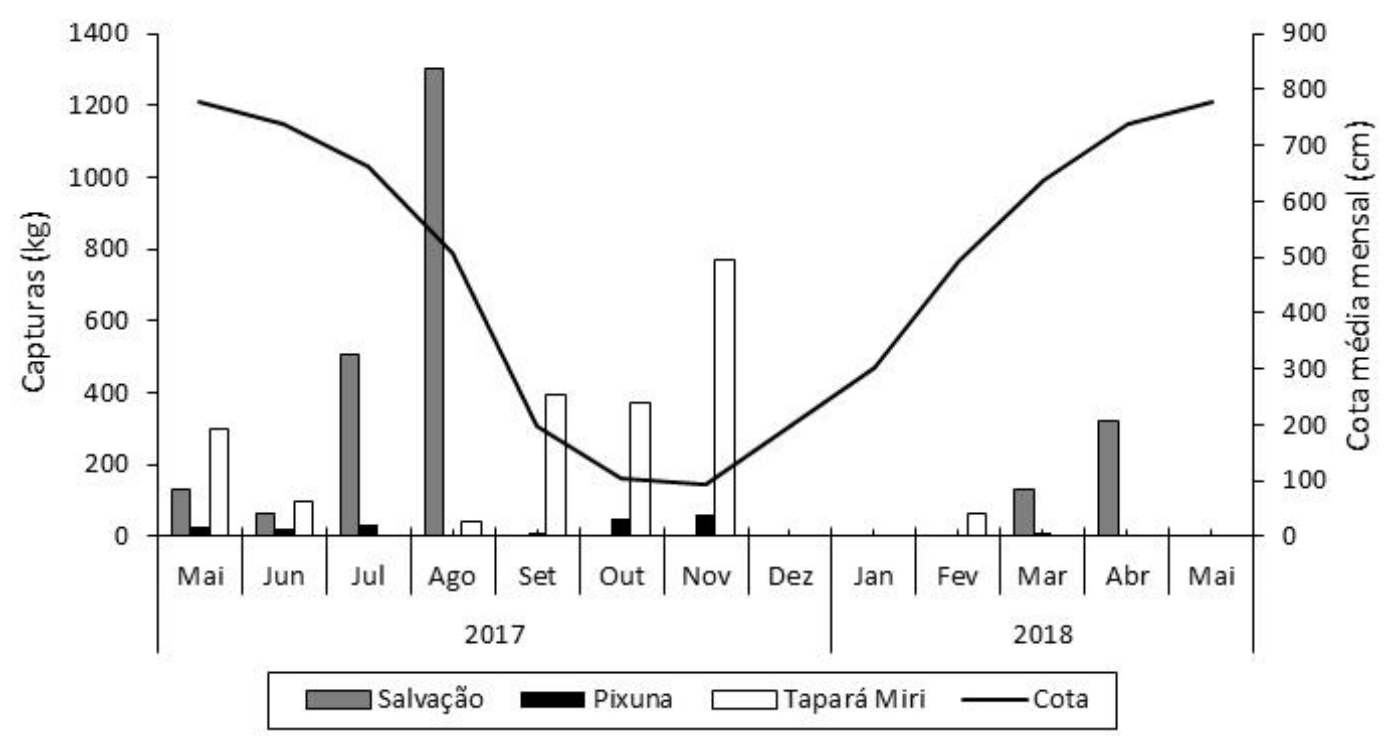

Dentre as comunidades estudadas, a Comunidade Salvação é a que mais captura acari e de acordo com os pescadores, ele é o principal recurso pesqueiro da comunidade. Devido às dificuldades de logística não foi possível registrar as capturas de acari entre setembro a dezembro de 2017, mas para os meses amostrados registrou-se um volume total de $2.461 \mathrm{~kg}$ nas capturas de acari em Salvação. Nas demais comunidades, Tapará Miri e Pixuna, registrou-se capturas totais nos meses amostrados que corresponderam a $2.037 \mathrm{~kg}$ e $209 \mathrm{~kg}$, respectivamente. A média de produção anual de acari no Pixuna, durante os anos de 2004 a 2007, era de aproximadamente $1.500 \mathrm{~kg}$ (Castello et al. 2013).

Os entrevistados do Pixuna relataram que houve diminuição expressiva na quantidade de acari na comunidade, pois em meados de 2012 muitos filhotes de acaris eram capturados para serem utilizados como isca na pesca do pirarucu (Arapaima gigas). Com a percepção da diminuição da quantidade de acari, os pescadores estabeleceram uma regra no acordo de pesca comunitário onde ficou terminantemente proibida a captura de acarizinhos para qualquer fim. Iniciativas de acordos pesqueiros comunitários como esta são difundidas na Amazônia e são consideradas estratégias promissoras para o manejo da pesca (Benatti et al., 2003; Azevedo e Apel, 2004; Oviedo et al, 2016, Ferreira e Silva, 2017).

\section{Ambientes de pesca}

Quanto aos ambientes de pesca, observou-se que nas três comunidades os pescadores fazem uso de três principais ambientes para as pescarias de acari ao longo do ano, sendo o lago o mais explorado (91\%), seguido das baixas $(5 \%)$ e restingas (4\%). Na época em que o nível das águas começa a aumentar (enchente), entre os 
meses de dezembro a abril, até atingir seu clímax (cheia), entre os meses de maio a junho, a pesca do acari ocorre principalmente nos lagos, nas baixas e em áreas de restinga que já estarão inundadas a partir do mês de fevereiro, enquanto que na vazante e seca, as pescarias se concentram nos lagos, uma vez que as restingas e as baixas secam em virtude da contração do meio ambiente aquático da várzea (Figura 5).

Figura 5. Frequência absoluta do uso de ambientes de captura de acari ao longo do ano nas Comunidades Salvação (A), Pixuna (B) e Tapará Miri (C).
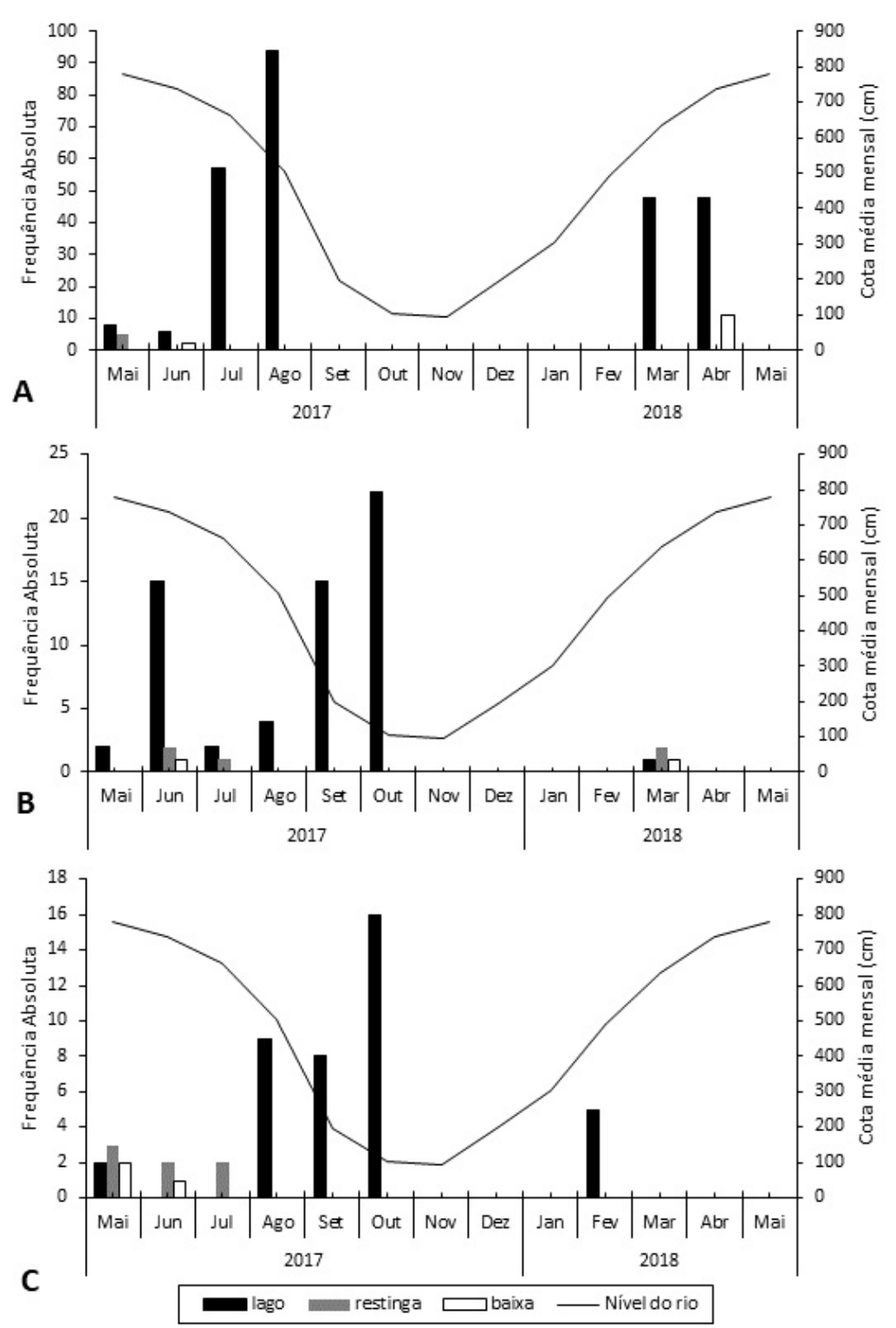

As inundações sazonais regulam a quantidade e a qualidade dos habitats disponíveis para populações de peixes nas áreas de várzea (Castello et al., 2019). Os ambientes identificados possuem classificações distintas. Os lagos de várzea são sistemas abertos, componentes de um sistema fluvial imenso e altamente dinâmico que podem está conectados ou não ao canal do rio (Junk 1983). As baixas é uma denominação local para as áreas inundadas, durante a cheia, ou encharcadas durante a seca, cuja vegetação é predominantemente herbácea. De acordo com Junk et al. (2015), as denominações locais de habitats e unidades de vegetação resultam de observações de longo prazo das populações humanas locais sobre as peculiaridades ecológicas e características biológicas e fornecem informações importantes sobre as funções do ecossistema. As restingas por sua vez, são os terrenos mais elevados, mas também suscetíveis à inundação durante o período de águas elevadas (McGrath et al. 1993). A identificação do uso dos ambientes da várzea para a pesca nos diferentes períodos do ano é essencial para o manejo desta atividade local. 
Como evidenciado neste estudo, os ambientes lacustres da várzea são de elevada importância para a pesca artesanal na Amazônia (Batista et al. 2012; Isaac et al. 2016). A ictiofauna que habita os lagos de várzea possui dinâmica complexa de comportamentos, conforme as flutuações do nível da água. Existem as espécies (migratórias) que fazem uso desses ambientes em algum período do ano, enquanto outras (sedentárias) não realizam migrações sistemáticas, permanecendo nos ambientes tradicionais ou realizando, caso necessário, apenas pequenos movimentos laterais na vazante e na seca entre o lago e as áreas que alagam sazonalmente (Isaac et al. 2012).

Neste estudo não foram registradas capturas de acari em ambientes de rios em razão da bioecologia desse peixe que apresenta comportamento predominantemente sedentário, ou seja, habita e completa o seu ciclo de vida em ambientes de águas lênticas, como lagos e áreas alagáveis, não necessitando de deslocamento pelos rios para desovar ou para se alimentar (Soares et al. 2008; Chapman et al. 2012). Portanto, os lagos são ambientes essenciais para o manejo e conservação dos estoques de acari.

\section{Apetrechos e embarcacões}

De acordo com os entrevistados, o apetrecho de captura do acari nos períodos de enchente e cheia é a malhadeira (redes de nylon e algodão de malhas variadas), enquanto que na seca a tarrafa (rede cônica com bordas chumbada) torna-se o principal apetrecho de pesca. A escolha dos apetrechos de pesca para determinada condição ambiental, geralmente reflete a interação profunda que os pescadores têm com o ecossistema aquático, permitindo-lhes a identificação de padrões sazonais na distribuição e abundância das espécies capturadas, bem como a exploração de diversos ambientes (Batista et al. 2012; Doria et al. 2014). Todavia, na área estudada, a escolha dos apetrechos para a captura de acari nos diferentes períodos também está condicionada às regras dos acordos de pesca estabelecidas pelas comunidades. Por exemplo, na estação seca a pesca com malhadeiras é proibida nos principais locais com o intuito de evitar a sobreexploração do recurso, uma vez que neste período os peixes ficam mais vulneráveis à pesca.

Os pescadores comumente utilizam embarcação do tipo canoa com motor de propulsão, conhecida localmente como rabeta, e canoas à remo para o deslocamento até os locais de pesca. Essas embarcações possuem características rústicas, sem estruturas para armazenamento e conservação do pescado e são amplamente utilizadas nas pescarias artesanais de pequena escala na Amazônia (Viana 2004; Lima et al. 2016; Flexa et al. 2016).

\section{Comercialização do acari}

Todos os entrevistados capturam acari para o consumo de suas famílias e $67 \%$ também se dedicam ao comércio da espécie. Para esses pescadores, o melhor período considerado para a venda é entre maio (pico da cheia) e julho (início da vazante), pois há baixa oferta de acari nos mercados e alta procura pelos consumidores. Os pescadores afirmam ainda que neste período os acaris estão mais gordos, sendo os preferidos pelos compradores.

De fato, os peixes da várzea estão mais gordos nesta época, pois neste momento e principalmente em meses anteriores, quando os campos, as restingas e as florestas são alagadas, eles se alimentam intensamente em virtude da alta disponibilidade de alimentos, fase considerada de maior taxa de crescimento para as espécies ícticas associadas às áreas alagadas (Fabré e Saint-Paul 1998). O acari por ter hábito detritívoro, se alimenta de matéria orgânica em decomposição, encontra neste período um verdadeiro banquete, uma vez que há alta disponibilidade desse material nos ambientes lacustres, derivado das macrófitas aquáticas, restos de animais e da floresta inundada (Yossa e Araújo-Lima 1998; Santos e Ferreira 1999).

Os pescadores das comunidades não são especializados na captura de acari, uma vez que também capturam outras espécies, cujas mais citadas foram o tambaqui (Colossoma macropomum), a pirapitinga (Piaractus brachypomus), o pirarucu (Arapaima gigas), a curimatá (Prochilodus nigricans), o pacu (Myleus spp. e Mylossoma spp.), o aracu (Schizodon spp. 
e Leporinus spp.), o tucunaré (Cichla spp.), o surubim (Pseudoplatystoma spp.) e o camarão (Macrobrachium amaz̧onicum), esta última somente na Comunidade Salvação. Empreender esforços na captura de uma única espécie diante da variedade peixes que a várzea oferece não parece ser interessante. Além do mais, a distribuição e a abundância dos estoques pesqueiros têm padrões sazonais que são muito bem conhecidos pelo pescador. A paisagem, os ambientes, as características climáticas e a dinâmica sazonal de alagação na Amazônia determinam a distribuição e a ecologia dos recursos pesqueiros, e consequentemente o comportamento do pescador e da pesca (Isaac et al., 2012).

O acari apresenta característica peculiar de venda em relação aos demais peixes amazônicos. Nas três comunidades eles são vendidos in natura, em unidades e vivos. O acari é comercializado vivo em função do rápido processo de degradação após a sua morte, o que origina um forte odor, inviabilizando seu consumo. Isso fez com que o consumidor adquirisse o hábito de comprá-lo apenas vivo. De acordo com Moroni (2005) as enzimas que degradam o músculo do acari são produzidas no trato gastrointestinal, e para que a sua carne se conserve por mais tempo, é recomendado que o animal seja condicionado no gelo sem as vísceras logo após a sua morte. Essa condição pode torná-lo secundário muitas vezes na preferência dos pescadores, quando comparado às demais espécies de peixes, visto que para mantê-lo vivo é necessário aumentar os custos de produção.

Para os pescadores entrevistados, comercializar o acari vivo já faz parte da cultura local, e isso influencia a dinâmica das pescarias. Alguns deixaram de se dedicar ao comércio do acari devido algumas dificuldades relatadas nas entrevistas, como o maior cuidado para que o peixe não morra, desde a captura, onde é necessário vistoriar os apetrechos de pesca com mais frequência e trocar a água constantemente dos locais onde são armazenados (comumente as canoas são parcialmente inundadas para este fim), até o momento de venda do peixe.

O preço do acari é determinado de acordo com os seus comprimentos e, desta forma, eles são classificados em pequenos $(\cong 25 \mathrm{~cm}$ ) e grandes (a partir de $\cong 35 \mathrm{~cm}$ ). O preço médio do acari pequeno na Comunidade Salvação é de $\mathrm{R} \$ 1,09( \pm 0,25)$ (US\$1,00 = R \$3,83), enquanto que no Pixuna e no Tapará Miri, o preço médio é de $\mathrm{R} \$ 2,31( \pm 0,45)$ e $\mathrm{R} \$ 1,50( \pm 0)$, respectivamente. Por outro lado, os acaris grandes têm preço médio de $\mathrm{R} \$ 1,84$ $( \pm 0,52), R \$ 3,43( \pm 0,49)$ e $R \$ 2,12( \pm 0,25)$, nas comunidades Salvação, Pixuna e Tapará Miri, respectivamente. É sabido que a população do principal porto de desembarque do Baixo Amazonas, a cidade de Santarém, tem preferência por acaris grandes na hora de comprar o peixe (Braga et al., 2016). Talvez fosse interessante que as comunidades que vendem o acari para a cidade de Santarém, tivessem um sistema de comercialização somente com acaris grandes para suprir a demanda por esse pescado, que segundo os pescadores, são peixes muito bons de vender, pois o consumidor está sempre a sua procura nos mercados e feiras da cidade.

$\mathrm{Na}$ Comunidade Salvação, os pescadores comercializam o acari nas feiras e mercados da cidade de Alenquer principalmente para os atravessadores (intermediários de venda entre o pescador e o consumidor) que compram o peixe assim que é desembarcado. Na comunidade o peixe é vendido tanto para o consumidor, pessoas da própria comunidade, quanto para o atravessador. Os acaris de Tapará Miri são comercializados na própria comunidade, principalmente para os atravessadores, mas a venda também acontece para os consumidores da própria comunidade. Percebe-se a importância da figura do atravessador na cadeia de comercialização, os quais comumente residem na própria comunidade. Uma figura importante nesse contexto é o dono da embarcação que faz o transporte diariamente de pessoas e de cargas para a cidade de Santarém, incluindo os acaris que são transportados vivos em caixas plásticas com águas.

Essa característica também é observada na Comunidade Pixuna, com a diferença que alguns pescadores optam por vender o acari para os atravessadores em Santarém. Isto provavelmente acontece por que a comunidade é mais próxima à cidade, logo tem mais acesso. Para Castello et al., (2013), em nível comunitário, a pesca pode apresentar diferentes aspectos dependendo do tamanho da população, da distância em relação ao mercado mais próximo, da dependência econômica da pesca e demais atividades produtivas, das preferências de consumo, entre outros aspectos. Portanto, condições como as citadas acima precisam ser consideradas no manejo da pesca do acari conforme as particularidades das comunidades. 


\section{Produção de farinha de peixe (piracui)}

Observou-se que na Comunidade Salvação, o acari também é utilizado como matéria prima para a produção de piracuí, uma farinha do peixe muito apreciada no Baixo Amazonas. A produção do piracuí é feita de forma artesanal na própria comunidade pelos pescadores e suas famílias, na vazante e na seca, entre os meses de agosto a novembro, sendo vendido principalmente para os consumidores na "Feirinha da Salvação" que acontece semanalmente em um local improvisado na cidade de Alenquer. O piracuí é vendido em quilogramas, com preço médio de $\mathrm{R} \$ 22,65$, variando de $\mathrm{R} \$ 15,00$ a $\mathrm{R} \$ 25,00$ e também em sacolas plásticas com aproximadamente 300 (g), com preço médio de $\mathrm{R} \$ 10,00$. Essa variação no preço do quilograma de piracuí se dá em razão da dinâmica de abastecimento dos mercados, o preço é melhor em meados de agosto e setembro, pois os mercados ainda não estão abastecidos com o produto.

O processo produtivo do piracuí só acontece a partir do momento que o nível das águas diminui e a terra dos quintais das casas é exposta, local onde ocorre o processamento do acari. O processo de produção dura cerca de seis horas, sendo dividido em quatro principais etapas. Inicialmente os peixes são assados na brasa, logo após a carne é removida, em seguida a carne é macerada e na etapa final é feita a sua secagem ou "torra" em um tacho semelhante aos utilizados para a secagem da farinha de mandioca. Ao final do processo é obtido um produto com textura floculenta que pode ser armazenado por várias semanas.

Segundo Lourenço et al. (2011) o acari se mostra ideal para fabricação do piracuí pois apresenta baixo teor lipídico e é uma excelente fonte de proteínas. Porém, apesar das vantagens nutricionais, o piracuí mostra algumas limitações durante a sua produção, de forma tradicional e rudimentar, com meios tecnológicos reduzidos, que impõe restrições do ponto de vista da saúde e do comércio (Lourenço et al. 2011). Kluczkovski e Kluczkovski Jr (2013) observaram a presença de aflatoxinas (substâncias tóxicas produzidas por fungos) no piracuí comercializado na cidade de Manaus, no Estado do Amazonas. Para os referidos autores, a presença de tais substâncias pode ser explicada pela contaminação do ambiente, uma vez que o produto analisado era condicionado em temperatura ambiente, sem considerar os padrões de higiene.

Esses entraves são pontos críticos e se relacionam possivelmente à manipulação inadequada da matéria prima e do produto final, dos materiais e utensílios empregados, do armazenamento e da comercialização, além da própria qualidade do pescado utilizado. Recentemente os produtores de piracuí da região do Oeste do Pará passaram a contar com uma nova ferramenta de incentivo à produção quando a Agência de Defesa Agropecuária do Estado do Pará (Adepará) regulamentou a atividade por meio da portaria no 3.250 de 012 de setembro de 2018. Esta portaria normatiza a produção do piracuí com intuito de gerar um padrão de produção e garantir mais segurança aos produtores e consumidores de todo o Estado do Pará. Dentre as regras sanitárias presentes na portaria, estão o cuidado desde a lavagem adequada do pescado até a embalagem do produto. A Adepará prevê orientações aos produtores para incentivar a certificação da atividade.

$\mathrm{Na}$ Comunidade Salvação, estima-se que para se produzir $1 \mathrm{~kg}$ de piracuí são necessários em média 30 acaris grandes ou 50 acaris pequenos. Assim, com base no preço médio de venda em unidade do acari vivo e no preço médio do piracuí, o pescador ganha mais se vender o animal em unidade do que beneficiado, uma vez que o processo produtivo do piracuí despende tempo e trabalho. Além do mais, os pescadores podem estar utilizando na produção de piracuí, acaris menores do que aqueles que são vendidos vivos, o que pode colocar em risco os estoques locais da espécie.

\section{Comprimento médio dos peixes}

Foram amostrados 1.006 acaris entre as comunidades, sendo 540 exemplares na Salvação, 267 no Tapará Miri e 199 peixes no Pixuna. Os peixes com maiores comprimentos foram registrados no Tapará Miri com média de 
35,89 $( \pm 6,26) \mathrm{cm}$. Os acaris das comunidades Salvação e Pixuna tiveram comprimentos médios de 31,53 ( \pm 3,27) $\mathrm{cm}$ e 32,66 ( $\pm 5,33) \mathrm{cm}$, respectivamente. Houve diferença significativa $(\mathrm{p}<0,01)$ dos comprimentos médios entre as comunidades $\left(\mathrm{F}=13 ; \mathrm{p}=2,67 \times 10^{-6}\right)$. O teste de Tukey indicou que o comprimento dos acaris de Tapará Miri se difere dos comprimentos das demais comunidades.

Neves e Ruffino (1998) estimaram o comprimento médio na primeira maturação sexual do acari comercializados na cidade de Santarém em $25 \mathrm{~cm}$ para as fêmeas e $28 \mathrm{~cm}$ para os machos. Por outro lado, Sousa et al., (2019) estimaram em 22,3 cm esse mesmo parâmetro, para o acari proveniente da pesca comercial no município de Parintins no Estado do Amazonas. Assim, considerando os resultados de estrutura de comprimento obtidos neste estudo e os comprimentos médios de primeira maturação sexual reportados na literatura, pode-se inferir que os acaris capturados nas três comunidades estudadas tratam-se de indivíduos que já se reproduziram ao menos uma vez, fato relevante para a renovação dos estoques dessa espécie na área de estudo.

O comprimento médio de primeira maturação sexual de espécies ícticas de importância pesqueira é uma medida essencial nos programas de manejo da pesca, sendo um parâmetro que ajuda na definição de um tamanho mínimo de captura para determinada espécie (Santos et al. 2015). Até o momento não há na legislação vigente um tamanho mínimo de captura recomendado para o acari no Baixo Amazonas. Diante da relevância deste recurso para a região, é importante que esta medida seja levada em consideração pelos gestores da pesca para ajudar na proteção dos estoques desovantes. Além disso, é imprescindível que uma medida desse tipo seja criada, monitorada e avaliada após sua implantação para que se tenha o conhecimento dos verdadeiros impactos que tal ação pode provocar.

\section{Conclusões}

A importância do acari nas comunidades estudadas é constatada, uma vez que ele tem contribuído para a segurança alimentar e para a geração de renda das famílias ribeirinhas. Além do mais, o acari mostra-se como uma espécie com grande potencial para a sua utilização e o seu processamento, sendo um peixe com excelente aceitação nos mercados da região.

Neste estudo evidenciou-se que a Comunidade Salvação é a que mais utiliza o acari entre as comunidades alvo do estudo, merecendo uma atenção em especial nos programas de manejo da pesca, uma vez que os estoques locais podem estar sofrendo forte pressão em razão da sua utilização, o que pode afetar a saúde do recurso e, consequentemente, a alimentação e a economia dos pescadores que têm o acari como a principal fonte de proteína e de renda. Nas demais comunidades, o menor uso do acari reflete-se na conservação dos estoques, resultando em peixes maiores. Neste caso, possivelmente o esforço de pesca está sendo distribuído entre a captura de várias espécies, diminuindo com isso a pressão sobre o acari, diferentemente do que ocorre na Salvação, onde este peixe é o alvo das pescarias.

Os resultados aqui apresentados ajudam a entender como a pesca do acari está sendo desenvolvida atualmente na área de estudo e podem posteriormente ser traduzidos em elementos estratégicos para a gestão desta espécie emblemática da região.

\section{Agradecimentos}

Os autores agradecem aos pescadores das Comunidades Salvação, Tapará Miri e Pixuna do Tapará, às Colônias de Pescadores e Pescadoras Artesanais Z-20/Santarém e Z28/Alenquer, à Universidade Federal do Oeste do Pará (UFOPA) e ao Programa de Pósgraduação, Sociedade, Natureza e Desenvolvimento. O presente trabalho foi realizado com apoio da Coordenação de Aperfeiçoamento de Pessoal de Nível Superior - Brasil (CAPES) Código de Financiamento 001 


\section{REFERÊNCIAS}

Acauan RC, Branco JO, Teixeira B, Rodrigues JL, Polete M. 2018. A pesca artesanal no município de Penha (SC): uma releitura do contexto socioeconômico da atividade e da capacidade adaptativa do setor. Desenvolvimento e Meio Ambiente, 49: $150-166$.

Alencar CAG, Maia LP. 2011. Perfil socioeconômico dos pescadores brasileiros. Arquivos de Ciências do Mar, 44 (3): 12 -19 .

Almeida OT, Lorenzen K, Mcgrath, DG. 2006. Pescadores rurais de pequena escala e o co-manejo no Baixo Amazonas. In: Almeida OT. Manejo de Pesca na Amazônia Brasileira, p. 52-72.

Azevedo C, Apel M. 2004. Co-gestão: um processo em construção na várzea amazônica. Manaus: Pro-Várzea/IBAMA.

Batista VS, Isaac VJ, Fabré NN. 2012. A Produção desembarcada por espécie e sua variação por macrorregião Amazônica. In: Batista VS. Peixes e pesca no Solimões-Amazonas: uma avaliação integrada. Brasília: Ibama/ProVárzea, p. 107-133.

Bailey KD. 1982. Methods of Social Research. McMillan. Nova York, EEUU. 553 pp.

Benatti JH, McGrath DG, Oliveira ACM. 2003. Políticas públicas e manejo comunitário de recursos naturais na Amazônia. Ambiente \& Sociedade, 6 (2): 137-154.

Braga TMP, Silva AA, Rebêlo G. H. 2016. Preferências e tabus alimentares no consumo de pescado em Santarém, Brasil. Novos Cadernos NAEA, 19 (3): 189-204.

Cardoso RSE, Freitas CEC. 2012. The commercial fishing fleet using the middle stretch of the Madeira river, Brazil. Acta Scientiarum. Biological Sciences, 34 (3): 247-253.

Carvalho AR, Williams S, January M, Sowman M. 2009. Reliability of community-based data monitoring in the Olifants River stuary (South Africa). Fisheries Research, 96: 119-128.

Castello L, McGrath DG, Beck PSA. 2011. Resource sustainability in small-scale fisheries in the Lower Amazon floodplains. Fisheries Research, 110 (2) 356-364.

Castello L, McGrath DG, Arantes CC, Almeida OT. 2013 Accounting for heterogeneity in small-scale fisheries management: The Amazon case. Marine Policy, 38:557-565.

Castello L, Bayley, PB, Fabre NN, Batista VS. 2019. Flooding effects on abundance of an exploited, long-lived fish population in river-floodplains of the Amazon. Reviews in Fish Biology and Fisheries, 2: 487-500.

Castro AP, Silva SCP, Pereira HS, Fraxe TJP, Santiago SL. 2007. A Agricultura Familiar: Principal fonte de desenvolvimento socioeconômico e cultural das comunidades da área focal do Projeto Piatam. In: Fraxe TJP, Pereira HS, Witkoski AC. Comunidades ribeirinhas amazônicas: modos de vida e uso dos recursos naturais -Manaus: EDUA.

Castro F, McGrath DG. 2001. O manejo comunitário de lagos na Amazônia. Parcerias Estratégicas, 6 (12): 112-126.

Chapman BB, Skov C, Hulthen K, Brodersen J, Nilsson PA, Hansson LA, Bronmark C. 2012. Partial migration in fishes: definitions, methodologies and taxonomicdistribution. Journal of Fish Biology, 81(2): 479-99. 
Doria CRC, Lima MAL, Santos AR, Souza STB, Simão MOAR, Carvalho AR. 2104. O uso do conhecimento ecológico tradicional de pescadores no diagnóstico dos recursos pesqueiros em áreas de implantação de grandes empreendimentos. Desenvolvimento e Meio Ambiente, 30: 89-108.

Ferreira RR, Silva RE. 2017. Acordos de pesca como gestão dos recursos: O caso da Ilha de São Miguel, Santarém, Pará. Amazônica, Revista de Antropologia, 9(1): 156 - 178

Flexa CE, Silva KCA, Cintra IHA. 2016. Pescadores artesanais à jusante da Usina Hidrelétrica de Tucuruí, Amazônia, Brasil. Boletim do Instituto de Pesca, 42(1): 221-235.

Furtado LG. 1993. "Reservas pesqueiras", uma alternativa de subsistência e de preservação ambiental: Reflexões a partir de uma proposta de pescadores do médio Amazonas, pp. 243-276. In: Furtado L, Leitão W, Mello AF. (eds). Povos das Águas: Realidade e perspectiva na Amazônia. MPEG/UFPA, Belém.

Hallwass G, Schiavetti A, Silvano RAM. 2019. Fishers' knowledge indicates temporal changes incomposition and abundance of fishing resources in Amazon protected areas. Animal Conservation, 2019:1-12.

Inomata SO, Freitas CEC. 2015. Pesca Comercial no Médio Rio Negro: Aspectos econômicos e estrutura operacional. Boletim do Instituto de Pesca, 41(1): 79-87.

Isaac VJ, Silva CO, Ruffino ML. 2004. A pesca no Baixo Amazonas. In.: Ruffino ML. (ed.). A pesca e os recursos pesqueiros na Amazônia brasileira. Ibama/PróVárzea, Manaus, Brasil, pp. 185-209.

Isaac VJ, Fabré NN, Silva CO, Ruffino ML, Saint-Paul U. Ecologia da Fauna Íctica. 2012. In: Batista VS. Peixes e pesca no Solimões-Amazonas: uma avaliação integrada. Brasília: Ibama/ProVárzea.

Isaac VJ, Castello L, Santos Brasil PR, Ruffino ML. 2016. Seasonal and interannual dynamics of river-floodplain multispecies fisheries in relation to flood pulses in the Lower Amazon. Fisheries Research, 183: 352-359.

Junk WJ. 1983. Aquatics habitats in Amazonia. Environmentalist, 3:24 -34.

Junk WJ, Bayley PB, Sparks RE. 1989. The flood pulse concept in river-floodplain systems. Proceedings of the International Large River. pp. 110-127.

Junk WJ, Piedade MTF, Schöngart J, Wittmann F. 2015. A Classificação dos Macrohabitats das Várzeas Amazônicas. In: Nunes CC, Piedade, MTF, Junk WJ. Classificação e delineamento das áreas úmidas brasileiras e de seus macrohabitat. p.165.

Kluczkovski AM, Kluczkovski Junior A. 2013. Aflatoxin in fish flour from the Amazon Region. In: Razzaghi-Abyaneh M. (Ed.). Aflatoxins: recent advances and future prospects, p. 197-206.

Lima MAL, Doria CRC, Freitas CE. C. 2012. Pescarias artesanais em comunidades ribeirinhas na Amazônia brasileira: perfil socioeconômico, conflitos e cenário da atividade. Ambiente \& Sociedade, 15 (2): 73-90.

Lima MAL, Freitas CE, Moraes SM, Doria CRC. 2016. Pesca artesanal no município de Humaitá, Médio Rio Madeira, Amazonas, Brasil. Boletim do Instituto de Pesca, 42 (4): 914-923. 
Lourenço LFH, Santos DC, Ribeiro SCA, Almeida H, Araujo A.F. 2011. Study of adsorption isotherm and microbiological quality of fish meal type "piracuí" of Acari-Bodo (Liposarcus pardalis, Castelnau, 1855), Procedia Food Science,1 (11) 455-462.

Martelo J, Lorenzen K, Crossa M, McGrath DG. 2008. Habitat association of exploited fish species in the Lower Amazon river-floodplain system. Freshwater Biology, 53: 2455-2464.

Mccluskey SM, Lewison RL. 2008. Quantifying fishing effort: a synthesis of current methods and their applications. Fish and Fisheries, 9: 188-200.

McGrath DG, Castro F, Futemma C, Amaral BD, Calabria J. 1993. Fisheries and the evolution of resource management on the lower Amazon floodplain. Human Ecology, 21 (2): 167-195.

McGrath DG, Cardoso A, Almeida OT, Pezzuti J. 2008. Constructing a policy and institutional framework for an ecosystembased approach to managing the Lower Amazon floodplain. Environment, Development and Sustainability, 10: 677-695.

Minayo MCS. 2009. Trabalho de Campo: contexto de observação, interação e descoberta. In: Minayo MC, Deslandes SF, Gomes R. Pesquisa social: Teoria, Método e Criatividade. Petropólis, RJ. p. 61-77.

Morettin PA, Bussab WO. 2010. Estatística Básica. 6. edição ed. São Paulo.

Neves AM, Ruffino ML. 1998. Aspectos reprodutivos do acarí-bodó Liposarcus pardalis (Pisces, Siluriformes, Loricariidae) (Castelnau, 1855) do Médio Amazonas. Boletim do Museu Paraense Emílio Goeldi, série. Zoologia, 14(1): 77-94.

Moroni FT. 2005. Alterações post-mortem do músculo de acari-bodó, Liposarcus pardalis (Castelnau, 1855) conservado em gelo ou congelado e seu aproveitamento tecnológico. 2005. 150 f. Tese de doudorado. Universidade Federal do Amazonas.

O’Dwyer EC. 2005. A construção da várzea como problema social na Região do Baixo Amazonas. In: Lima D. Diversidade socioambiental nas várzeas dos rios Amazonas e Solimões: perspectivas para o desenvolvimento da sustentabilidade — Manaus: Ibama, ProVárzea.

Oviedo AFP, Bursztyn M, Drummond JA. 2015. Agora sob nova administração : acordos de pesca nas várzeas da Amazônia brasileira. Ambiente \& Sociedade, 8 (4):119-138.

Oviedo AFP, Bursztyn M. 2016. The Fortune of the Commons: Participatory Evaluation of Small-Scale Fisheries in the Brazilian Amazon. Environmental Management 57:1009-1023.

Pereira SH, Souza DSR, Ramos MM. 2007. A diversidade da pesca nas comunidades da área focal do Projeto Piatam. In: Fraxe TJP, Pereira HS, Witkoski AC. Comunidades ribeirinhas amazônicas: modos de vida e uso dos recursos naturais -Manaus: EDUA.

Ramires M, Clauzet M, Rotundo MM, Begossi A. 2012. A Pesca e os pescadores artesanais de Ilhabela (SP), Brasil. Boletim do Instituto de Pesca, 38(3): 231 -246.

Raseira MB. Monitoramento participativo dos acordos de pesca: como avaliar a captura de pescado. Manaus: Ibama/ ProVárzea, 2007.

Rocha MF, Poleto SL. 2009. Etnoictiologia de pescadores profissionais artesanais dos rios Araguaia e Garças nos Municípios de Barra do Garças-MT, Pontal do Araguaia-MT e Aragarças-GO. Revista Interdisciplinar, 2:1-15. 
Ruffino ML, Soares EC, Silva CO, Barthem RB, Batista VS, Estupinãn, G, Pinto, W. 2006. Estatística Pesqueira do Amazonas e Pará - 2003. Ibama-ProVárzea, Manaus.

Santos GM, Ferreira EJG. 1999. Peixes da Bacia Amazônica In: LOWE-McConnell, RH. Estudos ecológicos de comunidades de peixes tropicais. São Paulo, pp. 345-354.

Santos RS, Silva JPC, Costa MR, Araújo FG. 2015. O tamanho de primeira maturação como parâmetro para estabelecimento de tamanho mínimo de captura para corvina no Sudeste do Brasil. Boletim do Instituto de Pesca, 41(3): 507-518.

Serrão EM, Braga TMP, Coêlho YKS, Campos DPC, Santos AR, Imbiriba LC, Zacardi DM. 2019. Conhecimento tradicional dos pescadores sobre o comportamento reprodutivo dos peixes em um lago de inundação no Oeste do Pará, Brasil. Sociedade e Natureza, 31: 1-21.

Silva JT, Braga TMP. 2016. Caracterização da Pesca na comunidade de Surucuá (Resex Tapajós Arapiuns). Biota Amazônia, 3: 55-62.

Soares MGM, Costa EL, Souza FKS, Anjos HDB, Yamamoto KC, Freitas CEC. 2008. Peixes de lagos do Médio Rio Solimões. 2. ed. - Manaus: Instituto I-piatam.

Sousa RGC, Oliveira CM, Sant'Anna IRA, Marshall BG, Freitas CEC. 2019. Growth parameters and yield per recruit analysis for the armoured catfish Pterygoplichthys pardalis sampled in the Low Reach of the Amazonas River. Boletim do Instituto de Pesca, 45(2): 1-8.

Tomé-Souza MJF, Raseira MB, Fuffino ML, Silva CO, Batista VS, Barthem RB, Amaral ES. 2007. Estatística Pesqueira do Amazonas e Pará - 2004. Ibama/ProVárzea-Manaus.

Vaz EM, Rabelo YGS, Corrêa JMS, Zacardi DM. 2017. A pesca artesanal no no lago Maicá: aspecto socioeconômicos e estrutura operacional, Biota Amazônia, 4:6-12.

Verner D. Poverty in the Brazilian Amazon: An Assessment of Poverty Focused on the State of Para. 2004. Policy Research Working Paper. N3357. World Bank, Washington.

Viana JP. 2004. A pesca no Médio Solimões. In.: Ruffino, M. L. (ed.). A pesca e os recursos pesqueiros na Amazônia brasileira. Ibama/PróVárzea, Manaus, Brasil, p.245-268.

Vazzoler ADM. 1996. Biologia da reprodução de peixes teleósteos: teoria e prática. Maringá, Universidade Estadual de Maringá. 166pp.

Yossa MI, Araújo-Lima CARM. 1998. Detritivory in two Amazonian fish species. Journal of Fish Biology, 52: 1141-1153..

Zacardi DM, Ponte SCS, Silva AJS. 2014. Caracterização da pesca e perfil dos pescadores artesanais de uma Comunidade às margens do Rio Tapajós, Estado do Pará. Amazônia: Ciência e Desenvolvimento, 19: 129-148. 